\title{
TRADITIONAL ECOLOGICAL KNOWLEDGE: THE THIRD ALTERNATIVE (COMMENTARY)
}

\author{
RAymond Pierottit ${ }^{1,2,3}$ AND DANiel Wildcat ${ }^{2}$ \\ ${ }^{1}$ Division of Biological Sciences, University of Kansas, Lawrence, Kansas 66045-2106 USA \\ ${ }^{2}$ Department of Natural and Social Sciences, Haskell Indian Nations University, Lawrence, Kansas 66046 USA
}

\begin{abstract}
Contemporary Western attitudes concerning the management of natural resources, treatment of nonhuman animals, and the natural world emerge from traditions derived from Western European philosophy, i.e., they assume that humans are autonomous from, and in control of, the natural world. A different approach is presented by Traditional Ecological Knowledge (TEK) of indigenous peoples of North America. Although spiritually oriented, TEK converges on Western scientific approaches. TEK is based on close observation of nature and natural phenomena; however, it is combined with a concept of community membership that differs from that of Western political and social thought. TEK is strongly tied to specific physical localities; therefore, all aspects of the physical space can be considered part of the community, including animals, plants, and landforms. As a consequence, native worldviews can be considered to be spatially oriented, in contrast to the temporal orientation of Western political and historical thought. TEK also emphasizes the idea that individual plants and animals exist on their own terms. This sense of place and concern for individuals leads to two basic TEK concepts: (1) all things are connected, which is conceptually related to Western community ecology, and (2) all things are related, which changes the emphasis from the human to the ecological community as the focus of theories concerning nature. Connectedness and relatedness are involved in the clan systems of many indigenous peoples, where nonhuman organisms are recognized as relatives whom the humans are obliged to treat with respect and honor. Convergence of TEK and Western science suggests that there may be areas in which TEK can contribute insights, or possibly even new concepts, to Western science. TEK is inherently multidisciplinary in that it links the human and the nonhuman, and is the basis not only for indigenous concepts of nature, but also for concepts of indigenous politics and ethics. This multidisciplinary aspect suggests that TEK may be useful in resolving conflicts involving a variety of stakeholders and interest groups in controversies over natural resource use, animal rights, and conservation. TEK may also have implications for human behavior and obligations toward other forms of life that are often unrecognized, or at least not emphasized, in Western science. We present examples from community and behavioral ecology where a TEK-based approach yielded unexpected and nonintuitive insights into natural phenomena. Understanding of TEK may be useful in helping scientists respond to the changing public perceptions of science, and new cultural pressures in our society.
\end{abstract}

Key words: belief system; conservation; ecology; environment; Indian; indigenous; Native American; resource management; Traditional Ecological Knowledge.

Capitalism and communism are simply the opposite sides of the same eurocentric coin. What the world needs is not a choice between capitalism and communism, between one aspect of eurocentrism or eurosupremacism and another. What we need is a genuine alternative to the European tradition as a whole.

-Russel Means, Lakota

(quoted in Churchill 1995)

Manuscript received 12 January 1998; revised 11 June 1999; accepted 22 June 1999. For reprints of this Invited Feature, see footnote 1, p. 1249.

${ }^{3}$ E-mail: pierotti@falcon.cc.ukans.edu

\section{INTRODUCTION}

Over the last 100 years there has been considerable debate over the appropriate way in which Americans, and other peoples, should treat the natural world (Leopold 1948, Dunlap 1988, Wilson 1992, Smith 1996). Some advocate a pro-development extractive approach, in which natural resources are perceived largely in terms of their economic value to humans. This perspective dominated attitudes towards environmental issues and resource management until the 1960s (Dunlap 1988) and is currently exemplified by the "wise-use" movement (Lehr 1992). This viewpoint has been identified with the political right (Smith 1996); however, 
exploitative approaches may come from all shades of the political spectrum.

There also exist opposing models, which argue that nature and nonhuman animals must be protected from human interference, and that true conservation means setting aside tracts of land from which human settlements, and even humans themselves, may be excluded (Brinkerhoff Jackson 1994, Owens 1998). For example, the U.S. Wilderness Act of 1964 defines wilderness as space forever untrammeled by man (Owens 1998). This viewpoint has been identified with the political left (Wilson 1992, Smith 1996), but as with pro-development forces, "conservationists" are represented throughout the political spectrum.

Despite apparent differences, all Western attitudes toward nature come from the same European philosophical roots, i.e., Descartes, Bacon, and the Enlightenment (Smith 1996). In the writings of philosophers as different as Aristotle, Descartes, and Kant, it is assumed that humans are autonomous from, and in control of, the natural world (Mayr 1997). For example, John Locke (1952) argued that nature existed primarily for facilitating the comfort and convenience of humans. For our purposes, we assume the viewpoints we describe to be characteristic of the dominant cultures in modern Europe, North America, and Japan, where a large proportion of citizens live in industrialized societies in which nature is viewed as separate and "under control" (Smith 1996). People across the political spectrum in these societies view the natural world as consisting of "resources," which carries the implicit assumption that all of nature can be exploited, regardless of whether it is for economic or aesthetic purposes (e.g., Locke 1952). In addition, citizens of industrialized societies typically adhere to the perspective that nature can be defined as places that are separate from humans (Leopold 1948, Smith 1996, Owens 1998). Consequently, the problem is not lack of knowledge for effectively managing resources, but rather motivating humans to conserve (Anderson 1996).

We do not, however, review and analyze Western attitudes toward nature, since this topic has been extensively treated elsewhere (Smith 1984, 1996, Mander 1991, Deloria 1992, 1995, Jackson 1994). Our intention is instead to discuss the Traditional Ecological Knowledge (henceforth TEK) of Native American peoples (henceforth native), which we believe represents a third alternative, sharing elements with both extractive and conservationist approaches, yet remaining clearly distinct from both (Johannes 1989, Martinez 1994). We emphasize the TEK of Native Americans because of our personal experiences and knowledge, but acknowledge that forms of TEK are found in indigenous peoples throughout the world that share similar themes and approaches.

Some conservationists have contended that the approach they use is in the spirit of Native American or indigenous traditions (Pierotti and Wildcat 1997a, b). We argue that such associations are based upon false assumptions about the true nature of indigenous belief systems, because unlike Western philosophy, TEK assumes that humans are, and always will be, connected to the natural world, and that there is no such thing as nature that exists independent of humans and their activities (Deloria 1990, Pierotti and Wildcat 1997b, Owens 1998).

The connections that are a crucial aspect of TEK are based on a mixture of extraction, e.g., animals are taken as prey, combined with recognition of the inherent value and good of nonhuman lives (sensu Taylor 1992). Traditional knowledge is based on the premise that humans should not view themselves as responsible for nature, i.e., we are not stewards of the natural world, but instead that we are a part of that world, no greater than any other part (Pierotti and Wildcat 1997b). In this way TEK deals largely with motivating humans to show respect for nonhumans. The respect for the nonhuman inherent in TEK can constrain natural human tendencies towards overexploitation, because nonhumans are incorporated into the ritual representation of the community, and are considered as members of the community (Anderson 1996, Barsh 1997, Salmon 2000).

\section{Space, Time, and Traditional Knowledge}

In recent years there has been considerable discussion of differences between the worldviews and knowledge base of indigenous peoples, and that of the "dominant" or "Western" culture (e.g., Johannes 1989, Mander 1991, Suzuki and Knudtson 1992, Anderson 1996). One major difference between native peoples of North America and Western European immigrants to North America is that the latter look backward and forward in time to get a sense of their place in history, while native peoples look around them to get a sense of their place in history. This difference has been described as thinking temporally in the case of Western culture and as thinking spatially in the case of the native peoples (Deloria 1992).

The idea of human history existing independently of local places and the natural world is foreign to the native peoples of North America, because for them their history cannot be separated from the entire geography, biology, and environment to which they belong. "In the traditional (way of knowing), there is no such thing as isolation from the rest of creation" (Deloria 1990:17). The notion of thinking spatially can be seen in the native tradition of invoking and praying to the four horizontal directions, the sky, and the earth. A person making such prayers is acknowledging the space in which they live, and their understanding that the creative forces that shape their lives exist in the natural world that surrounds them in all of these directions. 
We cannot and do not attempt to offer a definitive treatment of all North American indigenous worldviews. The influence of local places upon cultures, and the corresponding diversity of peoples attached to those places, guarantees the existence of variation in the ceremonial and symbolic expressions of native worldviews. Our experience and research suggest, however, that there may exist a shared way of thinking and concept of community common to native peoples of North America, which we define as TEK (see also Anderson 1996). Despite both forced and voluntary relocations, native people have taken their TEK with them, which has allowed them to survive these experiences, and establish sacred places in their new homes (Owens 1998:164). This way of thought includes: (1) respect for nonhuman entities as individuals, (2) the existence of bonds between humans and nonhumans, including incorporation of nonhumans into ethical codes of behavior, (3) the importance of local places, and (4) the recognition of humans as part of the ecological system, rather than as separate from and defining the existence of that system.

Despite dislocations and forced removals, these ideas are part of the shared intellectual property of all native peoples we have studied and lived with during the last 10 years at Haskell Indian Nations University in Lawrence, Kansas. We consider TEK to be an intellectual foundation for an indigenous theory and practice of politics and ethics, centered on natural places and connection to the natural world, which is capable of generating a conservation ethic on the part of those who follow its principles. TEK is based upon empirical observations resulting from patient observation of the natural world and its patterns. TEK is inherently multidisciplinary because it links the human and the nonhuman, and is not only the basis for indigenous concepts of nature but also for concepts of politics and ethics. There are therefore no clearly defined boundaries between philosophy, history, sociology, biology, and anthropology in indigenous thought.

In essence, TEK requires one to be native to a place (see also Jackson 1994), and to live with nature (see also Wilson 1992), in contrast to the dominant Western worldview, which assumes humans live above, separated, or in opposition to nature (Mander 1991, Suzuki and Knudtson 1992, Anderson 1996). To live with the geography and biology of your environment without trying to alter it solely to meet human needs is our concept of what it means to be native to a place. TEK is expressed in the ability to experience a sense of place while casting off the modern Western view that "space" exists to be conquered.

We emphasize that TEK is very different than the comfortable and romantic image of the Rousseauian "noble savage." Living with nature bears little relationship to such concepts as "love of nature," "closeness to nature," "communing with nature," or "con- servation of nature," which are statements made by Western conservationists (see below and Anderson 1996). Those who feel that it is within their direct power to conserve nature typically also feel that they are in control of nature, and that nature should be conserved only insofar as it benefits humans, either economically or spiritually (Smith 1984). Within a TEKbased ethical system, nature exists on its own terms, and individual nonhumans have their own reasons for existence, independent of human interpretation. One way to think about this is that those who desire to dance with wolves must first learn to live with wolves as members of their ecological and social community.

Living with nature requires people to rearrange the customs and habits of their daily life. The origins of TEK are based in the knowledge that native societies existed under conditions of constant pressure on the resources upon which they depended, and that a means had to be found to convince communities and families to economize with regard to their use of natural resources (Anderson 1996). This ethic may have arisen from early experiences of Native Americans, as they realized that resources upon which they depended could disappear forever, e.g., local disappearances of species depended upon for food and other products may have led to development of an ethically based system of restraint with regard to hunting.

One such tactic involved representing sound ecological management in strongly ethical (or religious) terms, and developing a view of the environment that stressed specific concrete bonds between nature and the human community (Rappaport 1971, Deloria 1990, Anderson 1996). The cultural diversity of Native Americans reflects their intimate ties to the land and the biology of the places that they call home in specific social codes and institutions, rather than in some misty "union with nature", (Anderson 1996). Thus, TEK encompasses both science and religion, in the sense that religion is the ritual representation of the community, and a device for sanctioning moral and ethical codes (Durkheim 1961). "The task of the tribal religion. . is to determine the proper relationship that the people must have with other living beings" (Deloria 1992). In TEK, we suggest that religion embodies environmental knowledge; therefore, it is not surprising that TEK is based on and has considerable insight into the workings of nature, and in many ways converges closely upon the Western science of ecology.

\section{Traditional Knowledge And Ecological CONCEPTS}

Native peoples lack an immigrant experience within their memories (Deloria 1995). Native stories do not deal with the exact time when events happened, since they happened so long ago that they exist "on the other side of memory" (Marshall 1995:207). The worldviews and cultures of Native American peoples evolved in 
the environments of the continents of North and South America. Native peoples depended upon the animals and plants of these environments for food, clothing, shelter, and companionship, and as a result developed strong ties to these nonhuman lives. "Little emphasized, but equally as important for the formation of (Native) personality was the group of other forms of life which had come down over the centuries as part of the larger family" (Deloria 1990:16-17). As these places and beings existed and changed along with them for thousands of years, native peoples developed their sense of place that led them to think spatially, along with their flexible knowledge base. These values have been kept intact through TEK, regardless of whether the people have been forced off their original lands, either by changing ecological conditions or by European immigrants (Owens 1998).

The body of knowledge acquired through careful observation came to constitute much of what Native Americans regard as TEK. One major theme of TEK is that all things are connected, which is not simply a homily or a romanticized cliche, but instead is a realization that no single organism can exist without the web of other life forms that surround it and make its existence possible. This concept is closely related conceptually to the Western discipline of community ecology, and like community ecology, it places emphasis on interrelationships between different species and individuals, and describes these interactions by employing the metaphor of a web. TEK also shares concepts based on connectedness with physiological and biochemical science related to the ecological concept of nutrient cycles (Pierotti and Wildcat 1997b). Thus, although the idea of a cycle, or circle, of life is an integral part of Native spiritual beliefs, this is not a mystical concept based upon great mysteries, but a practical recognition of the fact that all living things are literally connected to one another.

As a result of these connections with the nonhuman world, native peoples do not think of nature as "wilderness," but as home. Natives do not leave their "house" to "go into nature," but instead feel that when they leave their shelter and encounter nonhumans and natural physical features that they are just moving into other parts of their home (Reichel-Dolmatoff 1996). "What we call nature is conceived by Native peoples as an extension of biological man, and therefore a (Native) never feels 'surrounded by nature.' A (Native) walking in the forest, or paddling a canoe is not in nature, but he is entirely surrounded by cultural meanings his tradition has given to his external surroundings" (Reichel-Dolmatoff 1996:8-9). Thus, nonhuman elements are incorporated into the ritual representation of the community, establishing a nature-centered belief system (see above). At its roots, Western ecology employs a similar concept since the word "ecology" comes from "oikos," the Greek word for house, there- by acknowledging nature as the house of the human species.

Within TEK the shared ideas of connectedness and nature as home have profound implications for native conceptions of politics and ethics. Unlike dominant Western political and ethical paradigms, which find knowledge of how human beings ought to act imbedded in the life of one's social, i.e., human, relationships, native peoples found within TEK instructions concerning how a person should behave as a member of a community consisting of many nonhuman persons, e.g., four-leggeds, winged-ones, plants, and even landforms (Deloria 1990, 1992, Pierotti and Wildcat 1997b).

Western thought has traditionally followed the lead of Aristotle, and defined politics and ethics as exclusively human realms. Aristotle proposed that human values are learned from our fellow community members. From the perspective of TEK, Aristotle's basic reasoning was right, but his notion of community membership was wrong. TEK defines politics and ethics as existing in the realm of ecosystems, and would argue that it makes no sense to limit the notion of politics and ethics only to human beings (see also Salmon 2000). By limiting the definition of "persons" to human beings, however, Aristotle created a false and narrow sense of community and the corresponding spheres of political and moral life.

The inclusion of other living beings and natural objects into the category of persons, which includes human beings, requires politics and ethics that include these other community members. Consideration of nonhuman entities, including landforms, plants, and animals as individual persons who are part of their communities operates to keep humans attending to the specific entity and its particular value (Taylor 1992). This emphasis on individuality (see below) provides a spiritual alternative to overgeneralizing about nonhumans (Anderson 1996). One illustration of how native peoples include many other natural objects and living beings as members of their community is found in clan names and totems, which indicate covenants between certain human families and specific animals (Deloria 1990). These animals are connected to families over prolonged periods of time, and offer their assistance and guidance during each generation of humans. Throughout Native American cultures, there is a broad commonality of beliefs about animals in which human and nonhuman are bonded closely and part of one community involved with one another in terms of empowerment and emotional interactions (Anderson 1996).

It is frustrating to Native Americans to hear others speak romantically of our closeness to nature or love of nature. This relationship is more profound than most people can imagine, and the implications of this relationship carry uncomfortable consequences. To be Eagle, Wolf, Bear, Deer, or even Wasp clan means that 
you are kin to these other persons; they are your relations. Ecological connectedness is culturally and ceremonially acknowledged through clan names, totems, and ceremonies. In nearly all native stories animal- and plant-persons existed before human-persons (Pierotti and Wildcat $1997 a$ ). Thus, these kin exist as our elders and, much as do human elders, function as our teachers and as respected members of our community. Acknowledging nonhumans as teachers and elders requires that we pay careful attention to their lives, and recognize that these lives have meaning on their own terms (see also Taylor 1992).

This recognition of the value of nonhuman lives extends the social world to include animals as well as humans, and led to an ethical system that required proper treatment of the nonhuman. Humans live in mutual aid relationships with the nonhumans. If humans eat or otherwise use nonhumans, they are empowered by that relationship, which leads to mutual respect (Anderson 1996). Many nonhumans had powers far beyond the capabilities of ordinary humans, and were able to move with ease through worlds impassable to humans, e.g., air, water. Since animals were persons, and assumed to have some cognitive abilities, they were also assumed to recognize the danger when they were being hunted by humans. Thus if they were caught, it was also assumed to involve some element of choice on their part (Anderson 1996), hence the concept of the prey "giving itself to you." This presumed gift required gratitude (thanks), as well as respectful treatment of the nonhuman remains on the part of the human who took the life of the nonhuman (see also Tanner 1979).

The relationships of native peoples to nature have often been described in terms like "harmony with nature." Such descriptions project a rather amorphous, sentimental, and romanticized character to this relationship, but overlook the empirical knowledge of the lives of plants and animals that was such a major component of the daily lives of native peoples. The attitudes and relationships of native people to other organisms result from having evolved as distinct cultures in strong association with those other creatures, and experiencing them on a daily basis.

To native peoples, ecology and religion are inseparable, and thus religion serves to code ecological knowledge (Rappaport 1971, Deloria 1992, Anderson 1996). This religion then provides direct emotional involvement with the nonhuman world. For example, Northwest Coast Indians treated nonhuman beings with a combination of a sense of direct personal empowerment, and a healthy respect or even fear (Anderson 1996:66). To these peoples, "Fish, bears, wolves, and eagles were part of the kinship system, part of the community, part of the family structure. Modern urbanite ecologists see these as Other, and romanticize them, but for a Northwest Coast Indian, an alien human was more Other than a local octopus or wolf" (Anderson 1996:66).

Adherents to TEK also recognize that animals existed before humans did. In Rock Cree cosmogony, animals were recognized to have existed before human beings, and humans were known to come from animals during the progression of the earth (Brightman 1993). Thus, adherents to TEK are untroubled by the idea that humans came from nonhuman organisms. "Sungmanitu Tanka Oyate, (wolves), were a nation long before human beings realized and declared themselves a nation" (Manuel Iron Cloud [Oglala Lakota] in McIntyre 1995). Recognition of this similarity and connection between human and nonhumans leads also to the TEK concept that all things are related, a concept that is less than 150 years old in Western thought. Darwin's (1859) demonstration that humans must have evolved from nonhuman ancestors was such a revolutionary concept because it ran counter to prevailing Western philosophy, from Aristotle to Kant. Perhaps the most important consequence of Charles Darwin's theory of common descent was its change in the position of humans from separate from nature to part of nature (Mayr 1997:182). Darwin's accomplishment served to establish in Western thought one of the long-standing tenets of TEK, i.e., humans are related to nonhumans and irrevocably connected to the natural world.

One aspect of TEK often unrecognized is the emphasis that not only are humans dependent upon the nonhuman, but also that the reverse is often true. Activities of humans are often important in shaping the lives and ecology of the nonhuman. Burning practices of the indigenous peoples of both North America and Australia have major effects on local community structure and lead both to increased biodiversity and increased population size of many important species (Lewis 1989). In contrast, both Western science and popular culture have considered "wildfires" to be both "highly disruptive and environmentally destructive," and only very recently has Western science come to realize the value of fire as both an important component of community ecology and as a management tool.

It is also important to emphasize that TEK leads its adherents to identify with predators (Tanner 1979, Buller 1983, Brightman 1993, Marshall-Thomas 1994, Marshall 1995), which means they recognize that they must take lives in order to live themselves. Native people also recognize that they may be potential prey for other large carnivores, which is opposed to the prevailing idea in Western culture that any predator that takes a human life must be killed as if it were a criminal. This knowledge of connectedness and ecological similarity allows native people to respect predators, since they know how difficult it is to take the lives of other individuals (Tanner 1979). It is also recognized that predation is not a hostile act, and that nonhuman predators may feel strongly connected to the prey when 
they have taken its life (Marshall-Thomas 1994; R. Pierotti, unpublished observations).

All predators were respected for their strength and their weapons, but one predator spoke particularly to many native peoples, e.g., Comanche, Shoshone (Buller 1983), Blackfeet, Lakota (Marshall 1995, McIntyre 1995), and Northwest coastal tribes (Anderson 1996). This was wolf, Canis lupus, who was found throughout North America, lived in family groups, and was not strong or swift enough to kill large prey alone. Wolves working cooperatively as a group, however, could bring down even large plant eaters. Their weapons were "formidable, but the first people saw that they were of little use without endurance, patience and perseverance... qualities the first peoples could develop in themselves" (Marshall 1995:6). More important, however, was that if people were to emulate the wolf, they also had to exist to serve the environment, and to accept the connectedness of life. "Understanding this reality made them truly of the earth, because every life ultimately gives itself back to the earth" (Marshall 1995: 6-7). Western scientists studying wolves have realized that native people have far greater knowledge of the behavior and ecology of wolves than Western science, and have turned to native people to help them in their study of these animals. For example, an Alaskan wolf biologist has described the difficulty he had in locating active dens until he turned to local Inupiaq hunters for help (Stephenson 1982).

As in this last example, employment of TEK and its emphasis on connectedness between organisms can reveal connections between species unknown to, or unrecognized by ecologists. For example, during a study of beluga whales, Delphinapterus leucas, in the Bering Sea, it was noted that beluga no longer entered certain rivers. The indigenous people attributed this to the presence of beavers, which confused ecologists involved in the study until it was explained that beaver build dams in streams where salmon spawn, and that since salmon no longer used these rivers, the beluga, which fed upon the salmon, had ceased to use these rivers (Huntington and Myrmin 1996).

Another example comes from the TEK-based idea that badger and coyote were "friends" and hunted together. Western ecology, driven by the idea that competition among species drives community dynamics, categorized the relationship between coyote and badger as competition between these two predators (Minta et al. 1992). Recent study, however, revealed the empirical basis of this story. Coyotes and badgers wander around together, but when they see a squirrel, coyote gives chase. If the squirrel goes into a burrow, badger will dig up the burrow, or both will dig together. If the squirrel stays in the burrow, badger will often get it and have a meal. If the squirrel leaves by another burrow exit, coyote often gets it and has a meal. Food is not shared, but both coyote and badger catch more squirrels when they hunt together than when they hunt alone (Minta et al. 1992).

Our own research (R. Pierotti) into foraging associations between marine birds and mammals was influenced by the native idea that mixed species animal groups actually forage cooperatively, rather than competitively (Pierotti 1988a, b). The relationship between foraging marine mammals and associated gulls (Larus) was assumed to be competition, or at best commensalism in the Western scientific literature. However, we found that sea lions, dolphins, and even large whales use the conspicuous gulls to locate rich concentrations of patchily distributed fish and squid. The foraging activities of the mammals then serve to concentrate the prey at the surface, where the prey is much more accessible to the gulls, and as in the badger-coyote example, both groups experience a higher rate of feeding success as a result of their cooperation.

Similarly, the idea of an intergenerational conflict between adults and juveniles of the same species over care of unrelated offspring by nonrelatives (Pierotti 1988, 1991) was a result of traditional training that stressed recognizing the importance of individuals. The accepted scientific view of this "alloparental care" was that it was a result of either errors on the part of adults, or of kin selection (Riedman 1982). In contrast, by identifying and following individuals of both generations this conflict was recognized as a complex interaction between juveniles and adults. The juveniles sought adequate parental care, even from nonrelatives. Adults, depending upon specific ecological conditions, either (1) readily provided such care, or (2) did not give care when they could avoid it. The outcome of these behavioral interactions varied between years, even for the same individuals, and could not be simply predicted based upon genetic or other deterministic models.

\section{CONCLUSIONS}

TEK is a constantly evolving way of thinking about the world. Although views covered by TEK are described as "traditional," this should not be taken to mean that they cannot change. The essence of traditional beliefs is that they have existed long enough for long-range consequences to affect them (Anderson 1996). Use of the term traditional implies the repetition of a fixed body of data. Each generation, however, makes observations, compares their experiences with what they have been taught, and conducts experiments to test the reliability of their knowledge (Barsh 1997). TEK is linked to long-range consequences of human action and environmental change; therefore adherents to TEK should always be able to modify their activities and responses if environmental conditions so demand.

This reliance on new information as local conditions change reinforces the spatial orientation of TEK, in contrast to the temporal orientation of Western ethical 
systems (Deloria 1992). The spatial orientation of native peoples leads them to recognize that there are always new experiences and knowledge in the world, and transmission of TEK by oral traditions allows them to adjust in response to changing conditions. As a result, ethical and moral instructions for living are fit to the current ecological and historical context. In contrast, Western ethical behavior is derived from unchanging ideas (written words) that are thousands of years old, e.g., ancient Greek philosophers, the Bible, or the Koran. While these concepts may have been of crucial importance when they were first written down, they may be of little relevance to current ecological and social conditions. TEK derives from the physical, biological, and spiritual environment that is part of daily life (Deloria 1992), and the knowledge and experience gained through daily interaction with that environment. In TEK, the Western dichotomies of natural vs. supernatural, physical vs. metaphysical, sacred and profane, nature vs. nurture become largely meaningless. Experience, which emerges from local places, is the basis of both science and spirituality.

What will be gained by placing TEK-based worldviews into a broad-based system of knowledge is the ability to access a large amount of information and experience that has been previously ignored, or treated as mysticism. This additional knowledge, with its empirically derived emphasis on the natural world, can provide us with scientifically testable insights into some of the most pressing problems facing humankind today. The multidisciplinary structure inherent in TEK should make it relatively easy for knowledge and insights gained through TEK to be communicated among members of different disciplines, leading various stakeholders to negotiate more effectively with one another through a shared conceptual framework. As one Western scientist has put it "Imagine people who confidently assume they can best describe and manage the natural resources of an unfamiliar region alone-ignoring local hunters who know every cave and waterhole and the movements and behavior of a host of local species. Such, historically, has been the custom of most scientists and natural resource managers working in unfamiliar environments" (Johannes 1989:5).

To emphasize this point, we would like to close by relating an experience we are sure we share with many biologists, i.e., being asked "What good is the work that you do?" This question contains the hidden assumption that if what we do does not directly benefit human beings in some way it is without value. We often answer that our work teaches us more about the other members of our community and how to live with them, but most people of Western heritage appear confused by this answer, and do not understand this point. In contrast, if we give this answer to Native American elders, they are completely satisfied, for they under- stand implicitly what we are trying to accomplish, and its significance to humans.

\section{ACKNOWLEDGMENTS}

We thank the faculty and students of Haskell Indian Nations University for the knowledge and ideas that they have shared with us. We thank C. Annett, J. Ford, D. Martinez, M. Wildcat, and two anonymous reviewers for comments on drafts of this manuscript. This work was supported in part by NSF grant no. DEB-9317582 to R. Pierotti.

\section{Literature Cited}

Anderson, E. N. 1996. Ecologies of the heart: emotion, belief, and the environment. Oxford University Press, New York, New York, USA.

Barsh, R. L. 1997. Forests, indigenous peoples, and biodiversity. Global Biodiversity (Canadian Museum of Nature) 7(2):20-24.

Brightman, R. 1993. Grateful prey: Rock Cree human-animal relationships. University of California Press, Berkeley, California, USA.

Brinkerhoff Jackson, J. 1994. A sense of place, a sense of time. Yale University Press, New Haven, Connecticut, USA.

Buller, G. 1983. Comanche and coyote, the culture maker. Pages 245-258 in B. Swann, editor. Smoothing the ground University of California Press, Berkeley, California, USA.

Churchill, W. 1995. Since predator came: notes from the struggle for American Indian liberation. Aigis Publications, Littleton, Colorado, USA.

Darwin, C. 1859. The origin of species by means of natural selection. Studio Editions, London, UK.

Deloria, V., Jr. 1990. Knowing and understanding: traditional education in the modern world. Winds of Change 5(1): 1218.

Deloria, V., Jr. 1992. God is red: a native view of religion. Second edition. North American Press, Golden, Colorado, USA.

Deloria, V., Jr. 1995. Red earth, white lies. Harper and Row, New York, New York, USA.

Dunlap, T. 1988. Saving America's wildlife. Princeton University Press, Princeton, New Jersey, USA.

Durkheim, E. 1961. The elementary forms of the religious life. Free Press, Glencoe, Illinois, USA.

Huntington, H. P., and N. I. Myrmin. 1996. Traditional ecological knowledge of beluga whales: an indigenous knowledge pilot project in the Chukchi and northern Bering Seas. Inuit Circumpolar Conference, Anchorage, Alaska, USA.

Jackson, W. 1994. Becoming native to this place. University of Kentucky Press, Lexington, Kentucky, USA.

Johannes, R. E. 1989. Traditional ecological knowledge: a collection of essays. IUCN, Cambridge, UK.

Lehr, J., editor. 1992. Rational readings on environmental issues. Van Nostrand Reinhold, New York, New York, USA.

Leopold, A. 1948. A Sand County almanac. Cambridge University Press, Cambridge, UK.

Lewis, H. T. 1989. A parable of fire: hunter gatherers in Canada and Australia. Pages 7-20 in R. E. Johannes, editor. Traditional ecological knowledge: a collection of essays. IUCN, Cambridge, UK.

Locke, J. 1952 (reprint of 1690). Second treatise of government. Bobbs-Merril, Indianapolis, Indiana, USA.

Mander, J. 1991. The absence of the sacred. Sierra Club Books, San Francisco, California, USA.

Marshall, Joseph, III. 1995. On behalf of the wolf and the First Peoples. Red Crane Books, Santa Fe, New Mexico, USA.

Marshall-Thomas, E. 1994. The tribe of tiger: cats and their culture. Simon and Schuster, New York, New York, USA. 
Martinez, D. 1994. Traditional environmental knowledge connects land and culture. Winds of Change 9(4):89-94.

Mayr, E. 1997. This is biology: the science of the living world. Belknap Press, London, UK.

McIntyre, R. 1995. War against the wolf: America's campaign to exterminate the wolf. Voyageur Press, Stillwater, Minnesota, USA.

Minta, S. C., K. A. Minta, and D. F. Lott. 1992. Hunting associations between badgers and coyotes. Journal of Mammalogy 73:814-820.

Owens, L. 1998. Mixed-blood messages: literature, film, family, place. University of Oklahoma Press, Norman, Oklahoma, USA.

Pierotti, R. 1988a. Associations between marine birds and marine mammals in the Northwest Atlantic. Pages 31-58 in J. Burger, editor. Seabirds and other marine vertebrates commensalism, competition, and predation. Columbia University Press, New York, New York, USA.

Pierotti, R. 1988b. Interactions between gulls and otariid pinnipeds: competition, commensalism, and cooperation. Pages 213-239 in J. Burger, editor. Seabirds and other marine vertebrates: commensalism, competition, and predation. Columbia University Press, New York, New York, USA.

Pierotti, R. 1989. Intergenerational conflicts in species of birds with precocial offspring. Proceedings International Ornithological Congress. 19:1024-1029

Pierotti, R. 1991. Adoption vs. infanticide: an intergenerational conflict in birds and mammals. American Naturalist 138: $1140-1158$

Pierotti, R., and D. Wildcat. 1997a. Evolution, creation, and native traditions. Winds of Change 12:(2)73-77.

Pierotti, R., and D. Wildcat $1997 b$. The science of ecology and Native American traditions. Winds of Change 12(4): 94-98.

Rappaport, R. A. 1971. The sacred in human evolution. Annual Review of Ecology and Systematics 2:23-44.

Reichel-Dolmatoff, G. 1996. The forest within: the world view of the Tukano Amazonian Indians. Council Oak Books, Tulsa, Oklahoma, USA.

Riedman, M. L. 1982. The evolution of alloparental care and adoption in mammals and birds. Quarterly Review of Biology 57:405-435.

Salmón, E. 2000. Kincentric ecology: indigenous perceptions of the human-nature relationship. Ecological Applications 10:1327-1332.

Smith, N. 1984. Uneven development: nature, capital, and the production of space. Oxford University Press, Oxford, UK.

Smith, N. 1996. The production of nature. Pages 35-54 in G. Robertson, editor. FutureNatural: nature, science, culture. Routledge Press, New York, New York, USA.

Stephenson, R. O. 1982. Nunamiut Eskimos, wildlife biologists, and wolves. Pages 434-439 in F. H. Harrington and P. C. Pacquet, editors. Wolves of the world. Noyes Park Ridge, New Jersey, USA.

Suzuki, D., and P. Knudtson. 1992. Wisdom of the elders: sacred native stories of nature. Bantam Books, New York, New York, USA.

Tanner, A. 1979. Bringing home animals. C. Hurst and Company, London, UK.

Taylor, P. 1992. Respect for nature. Princeton University Press, Princeton, New Jersey, USA.

Wilson, A. 1992. The culture of nature: North American landscape from Disney to the Exxon Valdez. Blackwell, Cambridge, Massachusetts, USA. 